\title{
Microstructure and Corrosion Resistance of AA4047/AA7075 Transition Zone Formed Using Electron Beam Wire-Feed Additive Manufacturing
}

\author{
Andrey Filippov (D), Veronika Utyaganova *, Nikolay Shamarin, Andrey Vorontsov (D), Nikolay Savchenko (D), \\ Denis Gurianov (D), Andrey Chumaevskii, Valery Rubtsov, Evgeny Kolubaev and Sergei Tarasov * (1)
}

Institute of Strength Physics and Material Science, Siberian Branch of Russian Academy of Sciences, Akademicheskiy Pr., 634055 Tomsk, Russia; avf@ispms.ru (A.F.); shnn@ispms.ru (N.S.); vorontsov.a.583@gmail.com (A.V.); savnick@ispms.tsc.ru (N.S.); desa-93@mail.ru (D.G.); tch7av@gmail.com (A.C.); rvy@ispms.tsc.ru (V.R.); eak@ispms.ru (E.K.)

* Correspondence: filaret_2012@mail.ru (V.U.); tsy@ispms.ru (S.T.)

Citation: Filippov, A.; Utyaganova, V.; Shamarin, N.; Vorontsov, A.; Savchenko, N.; Gurianov, D.; Chumaevskii, A.; Rubtsov, V.; Kolubaev, E.; Tarasov, S.

Microstructure and Corrosion Resistance of AA4047/AA7075

Transition Zone Formed Using Electron Beam Wire-Feed Additive Manufacturing. Materials 2021, 14, 6931. https://doi.org/10.3390/ ma14226931

Academic Editor: Ana Pilar Valerga Puerta

Received: 11 October 2021

Accepted: 15 November 2021

Published: 16 November 2021

Publisher's Note: MDPI stays neutral with regard to jurisdictional claims in published maps and institutional affiliations.

Copyright: (C) 2021 by the authors. Licensee MDPI, Basel, Switzerland. This article is an open access article distributed under the terms and conditions of the Creative Commons Attribution (CC BY) license (https:// creativecommons.org/licenses/by/ $4.0 /)$.

\begin{abstract}
A gradient transition zone was obtained using electron beam deposition from AA4047 wire on AA7075 substrate and characterized for microstructures, tensile strength and corrosion resistance. The microstructure of the transition zone was composed of aluminum alloy grains, $\mathrm{Al} / \mathrm{Si}$ eutectics and Fe-rich and Si-rich particles. Such a microstructure provided strength comparable to that of AA7075-T42 substrate but more intense corrosion due to the higher amount of anodic $\mathrm{Mg}_{2} \mathrm{Si}$ particles. The as-deposited AA4047 zone formed above the transition zone was composed of aluminum alloy dendrites and interdendritic $\mathrm{Al} / \mathrm{Si}$ eutectics with low mechanical strength and high corrosion potential.
\end{abstract}

Keywords: additive manufacturing; aluminum alloy; functionally graded material; corrosion

\section{Introduction}

Functionally graded materials (FGMs) constitute a class of modern materials that allow the combination of unique physical, mechanical and chemical characteristics inherent in dissimilar materials into a single application or product. FGMs from aluminum alloys are fabricated with the use of various processes, such as gravitational, centrifugal or magnetic field-assisted casting [1,2], spark plasma sintering and infiltration [3]. Microstructures and defects formed in a transition zone between two dissimilar alloys are of special importance from the viewpoint of mechanical strength and corrosion. Therefore, great attention must be paid to studying and improving transition zone characteristics.

For instance, gravitational casting methods allowed the production of transition zones characterized by the presence of oxide and slug inclusions as shown by the example of AlSi7Mg0.3/AlSi12CuNiMg FGM [4]. Therefore, more effective casting methods were used, such as the centrifugal casting of such alloys as AA356, AA413 and AA390 to achieve the effect of grading the content of $\mathrm{Si}$ from hypoeutectic to hypereutectic [5]. Moreover, AA2014-SiC centrifugal cast and aged FGMs were obtained that allowed an improvement in their hardness and resistance to fatigue as compared to their standard cast states [6]. The wear resistance and strength characteristics of AA6061 and AA6061/SiC FGMs were also improved by centrifugal casting [7]. Al-Zn, Al-Ni and Al-Cu FGMs were obtained via directional solidification in a static magnetic field [8]. High-strength Al3003/Al6063 FGM was successfully fabricated using hot extrusion for multifunctional applications [9].

However, the use of the traditional above-described methods for fabricating FGMs does not allow the fabrication of complex-shaped void- and crack-free components with the desired composition gradient. Another drawback is a necessity to allow for extra thickness for further machining. 
Additive manufacturing is a fast-developing technology that is being increasingly more widely applied to mass-scale production, in particular, for direct energy deposition (DED) from wire by means of arc or plasma transferred arc additive manufacturing (WAAM) or electron beam additive manufacturing (EBAM).

DED methods possess a number of well-known advantages over other additive methods, such as selective laser melting (SLM) and spark plasma sintering (SPS). The DED process allows in situ control of the wire (wires) feed along with other process parameters, thus growing a near-net shape article even from dissimilar materials [10]. The layer-by-layer DED fabrication of FGMs is very difficult work not only from the viewpoint of selecting the appropriate process and adjusting its parameters but also due to the differences of the physical and chemical characteristics of the dissimilar materials used. The problems resulting from these differences in DED may even be unavoidable and insuperable from the viewpoint of obtaining functional, resilient and defectless FGMs [11].

WAAM is a rather simple process that provides a very high deposition rate, which, however, does not guarantee the absence of defects, such as pores, especially when building up thin walls from aluminum alloys [12-14]. The WAAM fabrication of thin-walled components from AA5356 and AA4047 was studied to show that both arc discharge length and pulse energy may have an effect on deposition accuracy [15]. SLM allows one to obtain good quality components from aluminum alloys [16-18], but obtaining zero porosity is a problem with this method even when using such alloy as AlSi10Mg [19].

The quality (and therefore the high costs of source powders) is another limitation of this method. Nevertheless, a Ti6Al4V / Al12Si FGM with brittle $\mathrm{TiSi}_{2}$ and $\mathrm{Ti}_{3} \mathrm{Al}$ intermetallic compounds (IMCs) in the transition zone was obtained using the laser engineered net shaping (LENS) method [20]. For example, an AlSi10Mg alloy was SLM deposited on an Al-Cu-Ni-Fe-Mg substrate with good adhesion [21]. A hybrid approach was proposed by Dolev et al., which allowed the expansion of the nomenclature of SLM-made Ti-6Al-4V high-strength articles [22].

EBAM allows the fine controlling and in situ monitoring of the process parameters, and, therefore, it is widely used for the growing variety of materials and components [23-28]. The application of EBAM on aluminum alloys is limited because of the evaporation of alloying elements, such as $\mathrm{Mg}$ and $\mathrm{Zn}$, which is the function of heat input. Nevertheless, there are examples of using EBAM for the fabrication of dense components from aluminum alloys [29-32], including those of the 7XXX and 2XXX series, which were inclined to hot cracking [33].

EBAM was successfully applied for the fabrication of defectless Cu-AISI 304 stainless steel FGMs by feeding two wires simultaneously [34,35]. A hybrid powder bed/wire EBAM allowed a fully dense CuAl-B ${ }_{4} \mathrm{C}$ FGM to be obtained [36]. Another attempt was devoted to growing an AA5356 wall on an AA7075 substrate [37] in order to improve the corrosion resistance of the latter. Admixing Mg into the AA7075/AA5356 transition zone proved to be detrimental for its corrosion resistance due to the precipitation of anodic $\mathrm{Al}-\mathrm{Cu}-\mathrm{Zn}-\mathrm{Mg}$ and $\mathrm{Mg}_{2} \mathrm{Si}$ particles. The as-deposited AA5356 zone was characterized by pure pitting corrosion due to the presence of anodic $\mathrm{Mg}_{2} \mathrm{Si}$ particles, which suffer $\mathrm{Mg}$ dealloying during corrosion and impair its corrosion resistance. Using a Mg-free aluminum alloy to form a transition zone on the AA7075 substrate would be interesting from the considerations mentioned above. Si is another component of $\mathrm{Mg}_{2} \mathrm{Si}$ detrimental particles, and, therefore, the effect of admixing it with a low $\mathrm{Mg}$ AA7075 metal in the transition zone has to be analyzed.

Aluminum 4XXX alloys contain silicon that attains high fluidity to the melt, provides low shrinking in solidification and good weldability. In addition, the good corrosion resistance of alloys such as AA4047 allows its use for the fabrication of cast engine blocks and wheels. Therefore, it could be worthwhile to fabricate a component that will combine the useful characteristics of alloys such as AA7075 and AA4047, i.e., high mechanical strength and corrosion resistance, respectively. It is unavoidable that some transition zone will form between these two parts whose mechanical and corrosion characteristics 
should be studied as dependent on the process parameters. The main characteristic of the EBAM that determines structural evolution in the transition zone is the heat input. It is desirable to adjust the heat input depending on the heat removal conditions and solidification during layer-by-layer deposition. Such an approach has previously been used on the AA7075/AA5356 system [37].

The objective of this work is to study the microstructures, mechanical characteristics and corrosion resistance of a transition zone formed by EBAM from an AA4047 wire on an AA7075 substrate.

\section{Materials and Methods}

Thin-wall samples (Figure 1c) were fabricated using layer-by-layer electron beam melting and deposition of AA4047 (Table 1) Ø $1.2 \mathrm{~mm}$ wire on an AA7075-T42 (hereinafter AA7075) (Table 2) $19.5 \mathrm{~mm}$ in height and $5 \mathrm{~mm}$ in thickness substrate. Residual pressure in the chamber was $-5 \cdot 10^{-5} \mathrm{~Pa}$. Deposition rate, wire feed rate, beam current and accelerating voltage were $380 \mathrm{~mm} / \mathrm{min}, 1344 \mathrm{~mm} / \mathrm{min}, 20 \mu \mathrm{A}$ and $30 \mathrm{kV}$, respectively. The wall dimensions (with substrate) were 95,39 and $5 \mathrm{~mm}$. The deposition strategy is shown in Figure $1 b$.
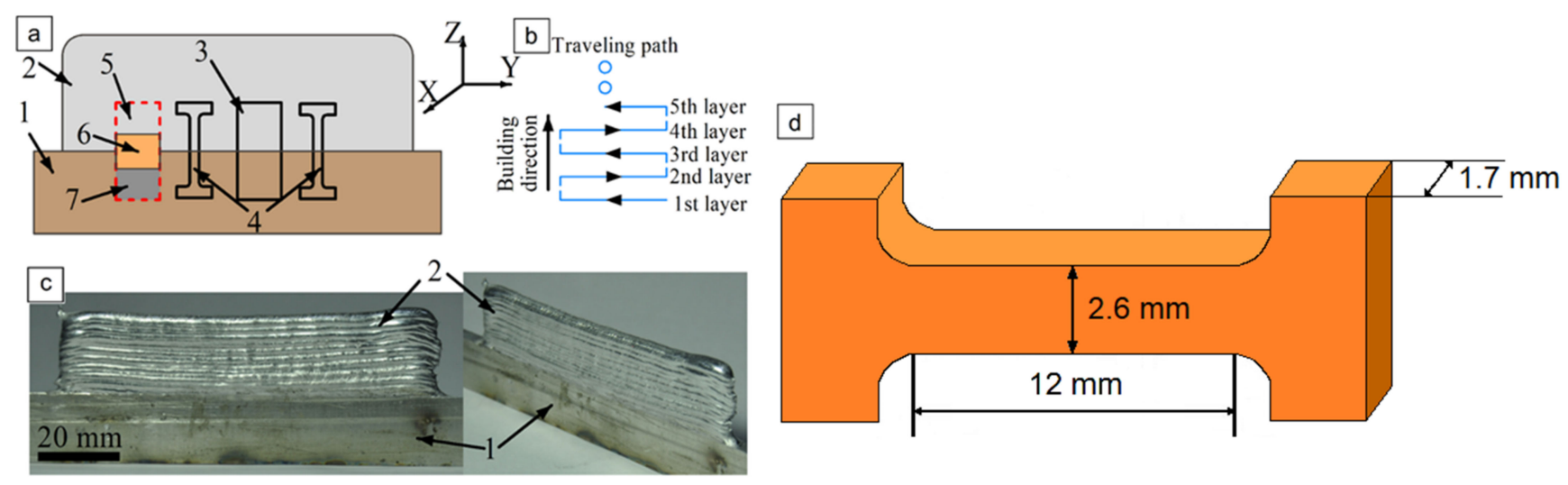

Figure 1. (a) Sample cut-off scheme; (b) deposition strategy; (c) additive-manufactured wall; (d) tensile sample with dimensions 1-AA7075 substrate; 2-as-deposited AA4047; 3-metallographic specimen; 4-tensile sample; 5-7-corrosion test samples.

Table 1. Chemical composition of AA4047 wire.

\begin{tabular}{ccccc}
\hline $\mathbf{A l}$ & $\mathbf{S i}$ & $\mathbf{F e}$ & $\mathbf{C u}$ & Ti \\
\hline Balance & 11.85 & 0.199 & 0.006 & 0.041 \\
\hline
\end{tabular}

Table 2. Chemical composition of AA7075 substrate [37].

\begin{tabular}{ccccccccc}
\hline Al & Zn & $\mathbf{C u}$ & $\mathbf{M g}$ & $\mathbf{F e}$ & $\mathbf{S i}$ & $\mathbf{M n}$ & $\mathbf{C r}$ & $\mathrm{Ti}$ \\
\hline Balance & $5-7$ & $1.4-2$ & $1.8-2.8$ & 0.5 & 0.5 & 0.4 & 0.1 & 0.05 \\
\hline
\end{tabular}

Samples were cut off from the printed wall and then characterized for microstructures, tensile strength, microhardness and corrosion resistance (Figure 1a). Samples for metallographic studies were prepared using mechanical grinding, polishing with the use of diamond pastes and etching in the Keller reagent (2 mL HF (48\%); $3 \mathrm{~mL} \mathrm{HCl} ; 5 \mathrm{~mL}$ $\mathrm{HNO}_{3} ; 190 \mathrm{~mL} \mathrm{H}_{2} \mathrm{O}$ ) for $2 \mathrm{~min}$. Optical confocal microscope Olympus (Olympus Scientific Solutions Americas, Waltham, MA United States), scanning electron microscope LEO EVO 50 (ZEISS, Oberkochen, Germany) attached with an EDS add-on, and transmission electron microscope JEOL JEM-2100 (JEOL Ltd., Tokyo, Japan) were used to study the microstructures and corroded surfaces of the samples. Phase composition was identified 
using an XRD instrument, DRON-7 (Burevestnik, Saint Petersburg, Russia), CoKa radiation, $\lambda=17,902 \AA$, operating at $36 \mathrm{kV}$ and $22 \mathrm{~mA}$ with a scan range of $15-165^{\circ}(2 \theta)$, step size of $0.05^{\circ}$ and counting time of $17 \mathrm{~s}$.

Microhardness was measured using a «Duramin-5» (Struers A/S, Ballerup, Danemark) microhardness tester at $50 \mathrm{~N}$ load. Tensile machine Testsystem 110M-10 (Testsystems, Ivanovo, Russia) was used for the determination of strength characteristics.

Corrosion testing in $3.5 \% \mathrm{NaCl}$ was carried out using a potentiodynamic method and an Electrochemical Instruments P-45X (Electrochemical Instruments, Chernogolovka, Russia) potentiostat. The samples that were cut off according to the scheme in Figure 1a were used as working electrodes, while the reference one was $\mathrm{Ag} / \mathrm{AgCl}$ with $3.5 \mathrm{M}$ solution of $\mathrm{KCl}$. A counter-electrode was a graphite rod.

\section{Results}

\subsection{Macro and Microstructures}

Samples for metallographic examination were machined from the EBAM built wall according to the scheme shown in Figure 1. A cross-section view allowed us to divide the built-up metal into three zones (Figure $2 b$ ), namely, top layer zone I, mid-height transition zone II and substrate zone III, which were represented by almost pure deposited AA4047, intermixed AA/4047/ AA7075 and heat-affected AA7075, respectively.



Figure 2. Microstructures in AA4047/ AA7075 sample. As-deposited AA4047 zone I (a); transition zone (b).

\subsubsection{Zone I}

Typical hypoeutectic as-cast structures represented by $\alpha-\mathrm{Al}$ dendrites and $\mathrm{Al} / \mathrm{Si}$ eutectics vertically grown along the building direction can be observed above the transition zone line (Figure 2a). A certain amount of both elongated and equiaxed particles can be found in this zone (Figure 3a,b). These particles are later identified as Al-Fe-Si ones using XRD and TEM. 

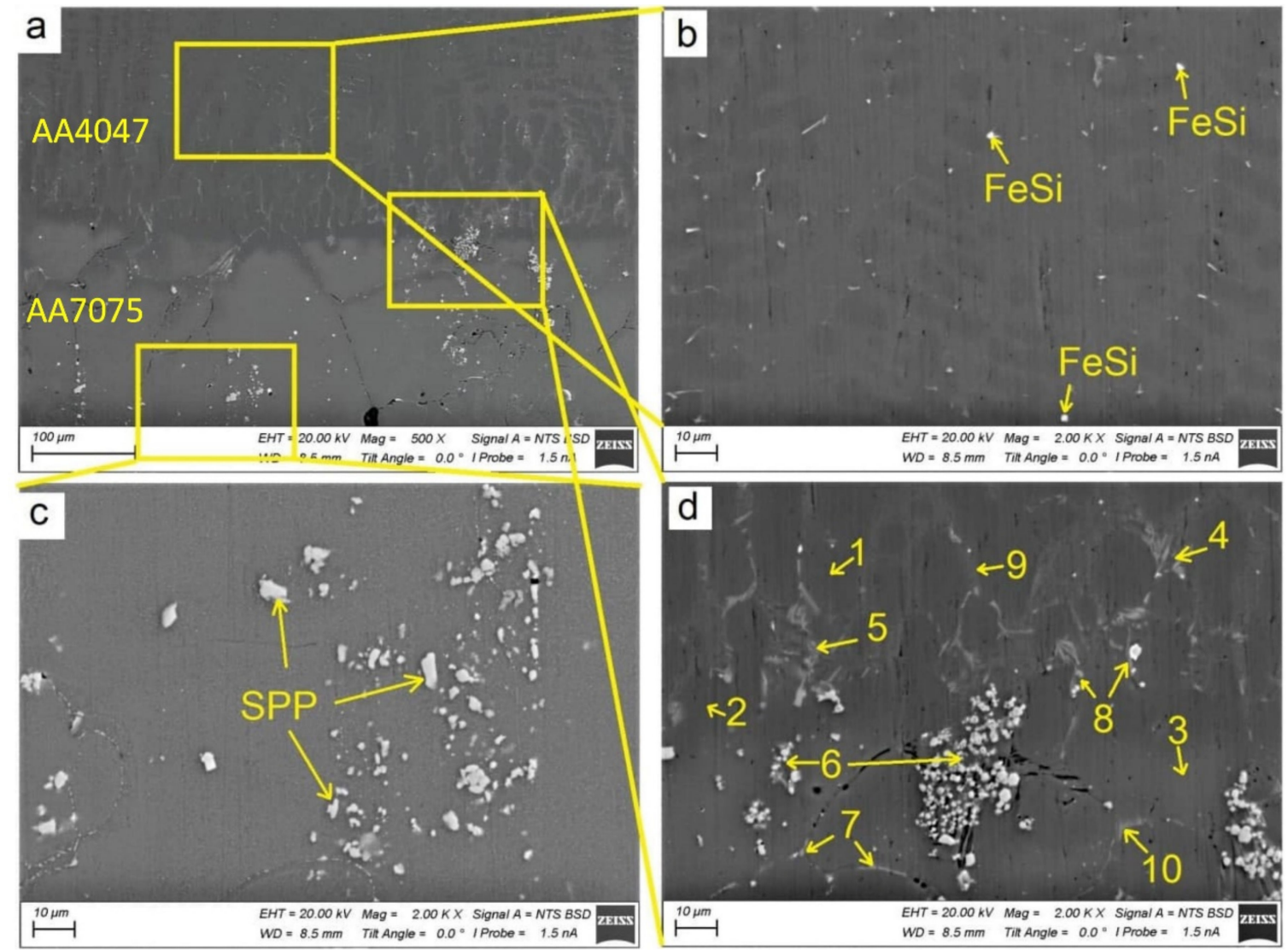

Figure 3. SEM BSE images of Al-Zn-Mg-Cu/Al-Si transition zone (a,d), Al-1i EBAM part (b), AA7075 substrate part (c). 1-3-Al-rich, 4-5-Si-rich, 7-8-Si-Mg-Cu-Zn, 9-10-Si-medium. SPP—secondary phase particles.

\subsubsection{Zone II}

The AA7075/AA4047 transition zone is in the form of a 150- $\mu$ m-thick layer composed of $\alpha$-Al grains with $\mathrm{Al} / \mathrm{Si}$ eutectics, formed due to the intermixing of both alloys in the melted pool, as well as coarse particles (Figure 2b, enlarged views, Figure 3a,d). Solidification of the melted pool in the transition zone starts from growing the Si-enriched $\alpha$-Al dendrites from partially melted AA7075 grains. Excess $\mathrm{Si}$ is forced out to the interdendritic spaces where the $\mathrm{Al} / \mathrm{Si}$ eutectics are then formed. The $\alpha$-Al dendrites (Figure $3 \mathrm{~d}$, position 1-3) are characterized by the presence of $<1$ at $\%$ concentrations of $\mathrm{Mg}, \mathrm{Si}, \mathrm{Cu}$ and $\mathrm{Zn}$ (Figure 4) and also contain small Si crystallites precipitated there from the already solidified $\mathrm{Al}$ (Figure $2 \mathrm{~b}$ ).

The $\mathrm{Al} / \mathrm{Si}$ eutectics are located at the $\alpha$-Al grain boundaries and in the particle agglomerates (Figure 3d, position 4-6), where the concentration of Si becomes higher than 30 at\% (Figure $4 \mathrm{~b}$ ). Another sort of particle, namely, grain boundary Si-Mg-Cu-Zn ones, with Si concentration $<10$ at $\%$ (Figure 4c), are observed in Figure 3d, position 7-8. Even less $\mathrm{Si}$ is detected in the grain boundary particle in Figure 3d, position 9-10.

\subsubsection{Zone III}

The microstructure of an AA7075 substrate is represented by coarse $100 \pm 25 \mu \mathrm{m} \alpha-\mathrm{Al}$ grains (Figure $2 b$ ). Coarse intermetallic particles are observed both inside the grains and on their boundaries (Figure $3 a, c)$. These particles were identified as $\eta-\mathrm{MgZn}_{2}, \theta-\mathrm{Al}_{2} \mathrm{Cu}$ and $\mathrm{S}-\mathrm{Al}_{2} \mathrm{CuMg}$ phases, which are commonly inherent in the AA7075 [37]. 




(a)

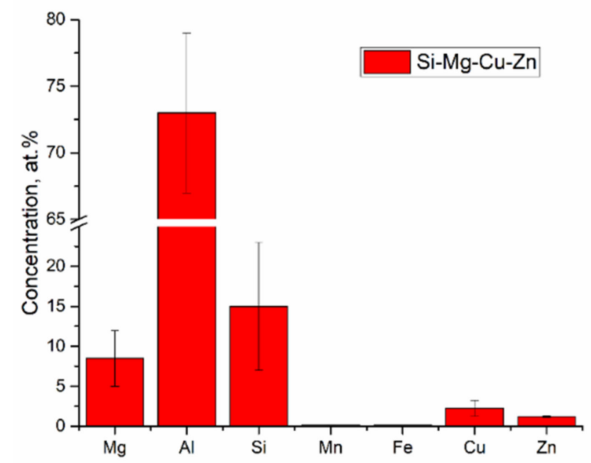

(c)

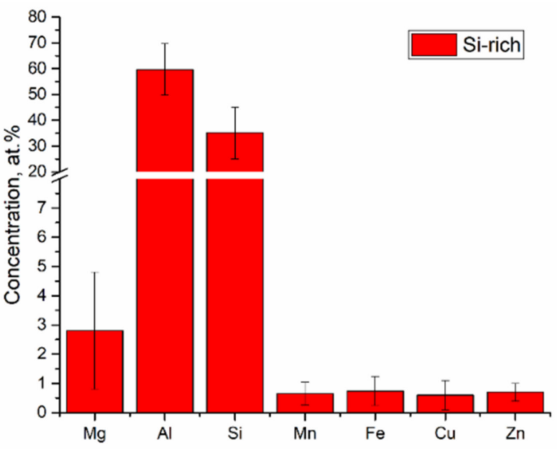

(b)

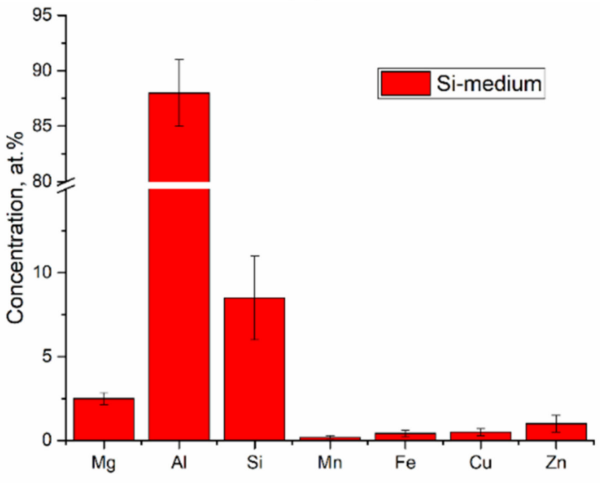

(d)

Figure 4. EDS element composition of particles shown in Figure 3. Al-rich (a), Si-rich (b), Si-Mg-Cu-Zn (c), Si-medium (d).

\subsection{Element Concentration Profiles and Phases in Transition Zone II}

EDS profiles for basic alloy elements as distributed across the transition zone show that the atomic concentration of magnesium, zinc and copper sharply reduce in the middle of the transition zone, while that of silicon sharply grows (Figure 5). It can also be noticed that the concentration of $\mathrm{Mg}$ becomes slightly higher starting from a wall height of $10 \mathrm{~mm}$; i.e., up to 2.5 at $/ \%$ of $\mathrm{Mg}$ was found in the as-deposited $\alpha-\mathrm{Al}+\mathrm{Al} / \mathrm{Si}$ eutectic layers.

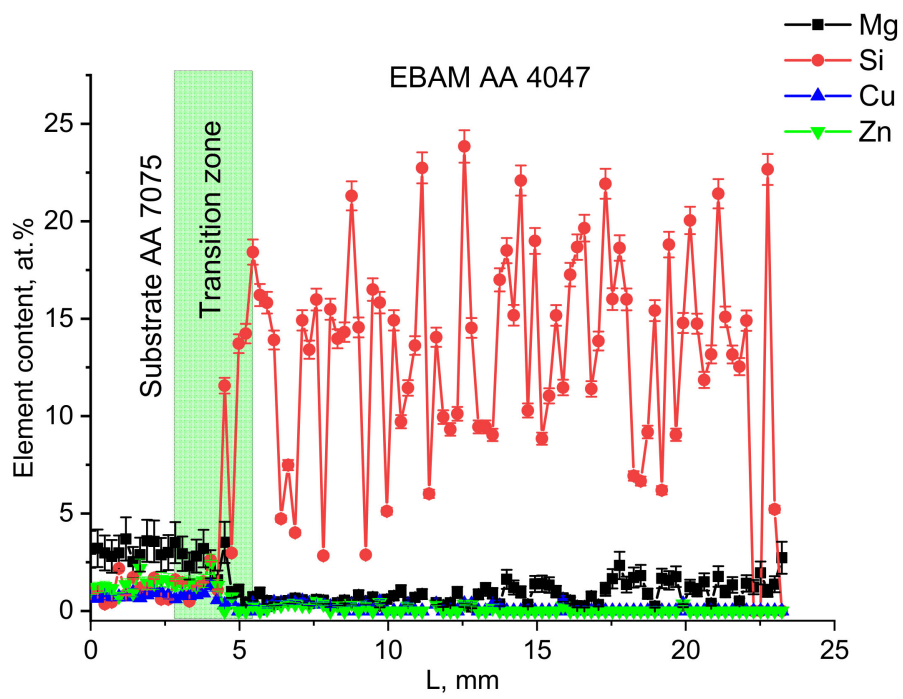

Figure 5. EDS profiles for $\mathrm{Mg}, \mathrm{Si}, \mathrm{Cu}$ and $\mathrm{Zn}$ as measured along the wall height.

The XRD patterns that were obtained from the transition zone (Figure 6) allowed for the identification of the presence of phases, such as $\alpha-\mathrm{Al}$, Si and $\mathrm{MgZn} \mathrm{n}_{2}$, which formed 
from intermixed AA7075/AA4047 metals (Figure 6). The $\mathrm{MgZn}_{2}$ phase was detected with the AA7075 substrate along with the $\alpha$-Al.



Figure 6. XRD patterns for AA7075 substrate, AA7075/AA4047 transition zone and deposited AA4047.

Some amount of $\mathrm{Si}$ was detected here, which descended from the above as-deposited AA4047 fully composed of $\alpha-\mathrm{Al}$ and Si phases. Despite the fact that the top part of the wall contains up to 2.5 at $\%$ of $\mathrm{Mg}$, no $\mathrm{Mg}$-containing phases were detected there using the XRD. Some slight peaks were found in the as-deposited AA4047, which could be related to Fe-Si-Al phases.

The $\alpha$-Al lattice parameter is changed along the wall height as shown in Figure 7 and in accordance with $\mathrm{Zn}, \mathrm{Cu}$ and $\mathrm{Mg}$ concentration profiles (Figure 5).

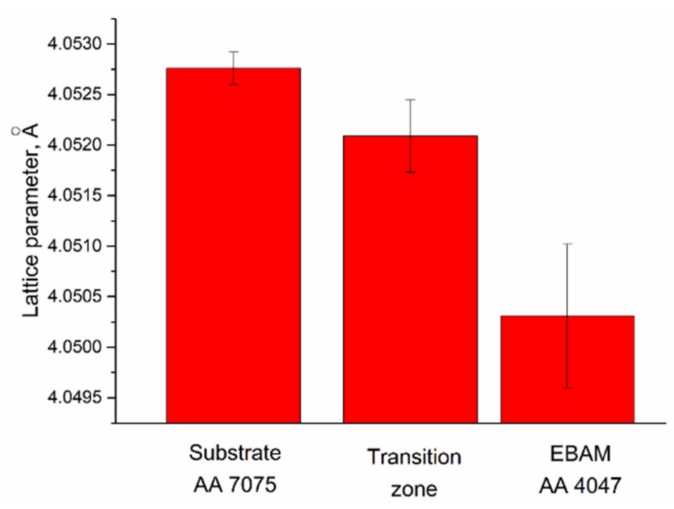

Figure 7. Solid solution lattice parameter as determined for AA7075 substrate, AA7075/AA4047 transition zone and deposited AA4047.

\subsection{TEM Study of Particles}

A TEM examination of particles in the AA7075 heat-affected zone has previously been carried out after the layer-by-layer deposition of AA5356 [37]. Therefore, it could be of more interest now to examine AA4047/ AA7075 transition zone II and AA4047 deposition zone I. 


\subsubsection{Transition Zone}

Several types of particles were detected in the thin foils cut off from the transition zone metal. According to EDS data, the particle (Figure 8, Table 3) located in the triple junction of $\alpha$-Al grains is composed of $v$-phase $\mathrm{Mg}-\mathrm{Zn}-\mathrm{Cu}-(\mathrm{Al})$ [38] and S-phase $\left(\mathrm{Al}_{2} \mathrm{CuMg}\right)$. Fine precipitates (Figure 8, position 7-9) are composed of $\mathrm{Al}, \mathrm{Zn}, \mathrm{Mg}$ and $\mathrm{Cu}$ (Table 3) with a high concentration of aluminum that does not allow their more accurate identification.

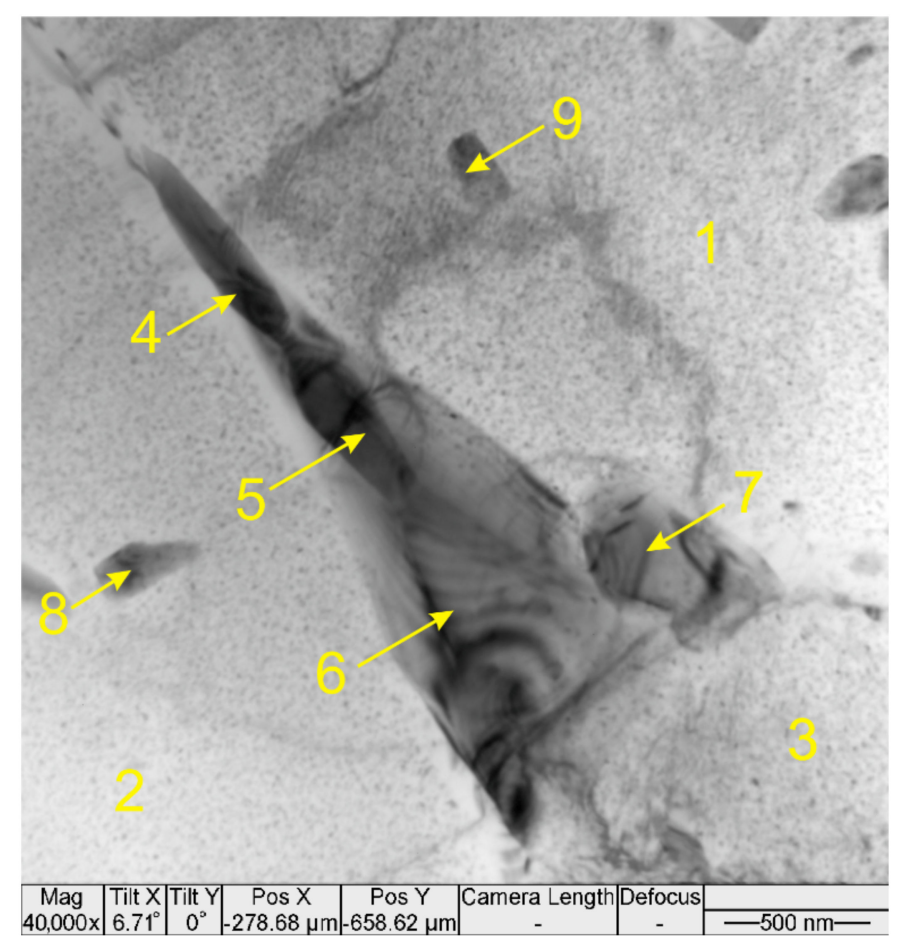

Figure 8. TEM image of a compound v-phase/S-phase particle in the AA4047/AA7075 transition zone.

Table 3. EDS of the compound particle in Figure 8.

\begin{tabular}{cccccc}
\hline Probe Point & $\mathbf{M g}$ & $\mathbf{A l}$ & $\mathbf{C u}$ & $\mathbf{Z n}$ & Phase \\
\hline $1-3$ & $1.50 \pm 0.08$ & $96.2 \pm 0.5$ & $0.60 \pm 0.05$ & $1.68 \pm 0.05$ & $\alpha$-Al \\
4 & $21.6 \pm 3$ & $56.8 \pm 4.5$ & $5.8 \pm 1.2$ & $15.9 \pm 1.6$ & v-phase \\
5 & $31.5 \pm 3$ & $36.9 \pm 4.2$ & $13.4 \pm 2.3$ & $18.1 \pm 3.1$ & $\mathrm{Mg}-\mathrm{Zn}-\mathrm{Cu}-(\mathrm{Al})$ \\
6 & $21.4 \pm 2.5$ & $59.4 \pm 6.1$ & $17.9 \pm 3$ & $1.3 \pm 0.1$ & S-phase $\left(\mathrm{Al} \mathrm{C}_{2} \mathrm{CuMg}\right)$ \\
7 & $12.3 \pm 4.0$ & $70.1 \pm 8.9$ & $4.5 \pm 1.25$ & $13.2 \pm 0.4$ & Al-Zn-Mg-Cu \\
8 & $10.6 \pm 0.1$ & $79.4 \pm 6.0$ & $3.1 \pm 1.1$ & $6.9 \pm 0.8$ & Al-Mg-Zn-Cu \\
9 & $5.2 \pm 0.9$ & $88.2 \pm 2.7$ & $2.2 \pm 0.4$ & $4.4 \pm 0.07$ & \\
\hline
\end{tabular}

Moreover, coarse $>2 \mu \mathrm{m}$ particles (Figure 9) that contain $\mathrm{Al}, \mathrm{Fe}, \mathrm{Mn}, \mathrm{Cu}$ and $\mathrm{Zn}$ (Table 4) can be found, whose precipitation from the melt is provided by the presence of these elements with AA7075. These particles have been identified as Fe-rich ones elsewhere [37]. Secondary Al-Zn-Mg-Cu particles (Figure 9, position 3-7) are located along the grain boundaries. Their accurate identification is difficult due to their size and, therefore, the detection of more aluminum in the matrix (Table 4, position 3-7). The rodlike (Figure 9, Table 4, position 8 and 9) and needle-like (Figure 9, Table 4, position 10) precipitates may be $\eta$-phase $\left(\mathrm{MgZn}_{2}\right)$ and S-phase $\left(\mathrm{Al}_{2} \mathrm{CuMg}\right)$. 


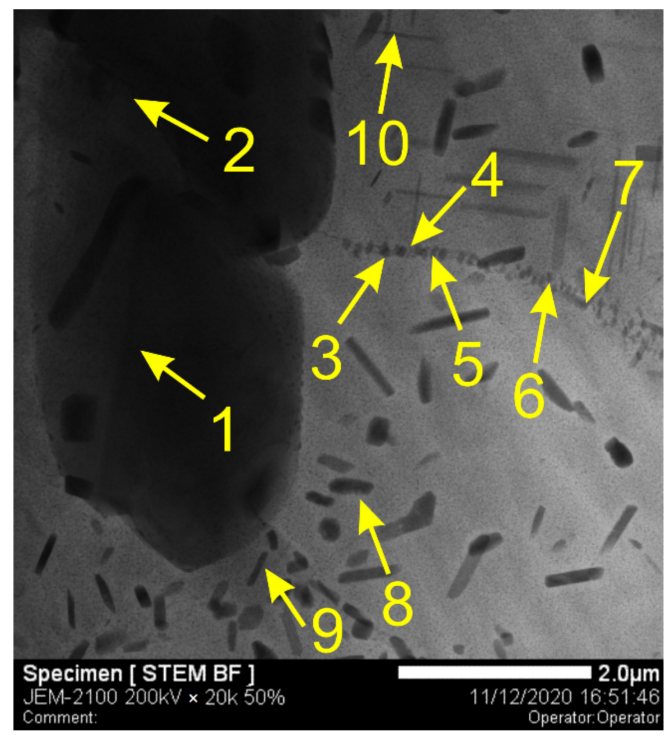

Figure 9. Coarse iron-rich particles and fine $\mathrm{Al}_{2} \mathrm{CuMg}$ and $\mathrm{MgZn}$ 2 precipitates in the $\mathrm{AA} 4047 /$ AA7075 transition zone.

Table 4. EDS of particles in Figure 9.

\begin{tabular}{ccccccc}
\hline Probe Point & Al & Mn & Mg & Fe & Cu & Zn \\
\hline $1-2$ & $68.7 \pm 1.3$ & $4.3 \pm 0.9$ & - & $17.9 \pm 1.4$ & $6.2 \pm 1.8$ & $2.9 \pm 0.4$ \\
3 and 6 & $82.9 \pm 0.3$ & - & $8.9 \pm 0.3$ & - & $6.6 \pm 0.2$ & $1.5 \pm 0.1$ \\
4 & $75.7 \pm 1.1$ & - & $13.8 \pm 0.6$ & - & $8.6 \pm 0.8$ & $1.8 \pm 0.1$ \\
5 & $90.9 \pm 2.1$ & - & $4.1 \pm 0.8$ & - & $3.1 \pm 0.3$ & $1.9 \pm 0.2$ \\
7 & $84.7 \pm 1.9$ & - & $5.7 \pm 0.9$ & - & $3.0 \pm 0.3$ & $6.5 \pm 1.7$ \\
8 & $74.7 \pm 1.6$ & - & $7.9 \pm 1.0$ & - & $0.8 \pm 0.1$ & $16.6 \pm 1.3$ \\
9 & $81.5 \pm 1.3$ & - & $5.7 \pm 1.3$ & - & $0.5 \pm 0.1$ & $12.3 \pm 1.0$ \\
10 & $80.2 \pm 1.4$ & - & $10.7 \pm 1.4$ & - & $8.1 \pm 0.9$ & $1.0 \pm 0.4$ \\
\hline
\end{tabular}

The third sort of particles are compound core-shell $\mathrm{Mg}_{2} \mathrm{Si} / \mathrm{v}$-phase ones (Figure 10, Table 5, position 1-4 and 5-6), which can precipitate from the melt at high solidification rates and the insufficiently fast diffusion of AA7075 components [38]. The rod-like precipitates can be S-phase $\left(\mathrm{Al}_{2} \mathrm{CuMg}\right)$ (Table 5, position 7) and $\eta$-phase $\left(\mathrm{MgZn}_{2}\right)$ (Table 5, position 8).

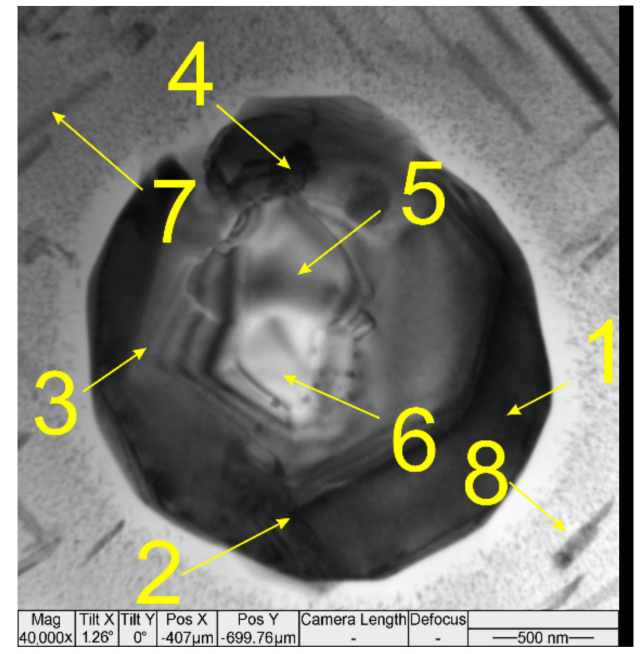

Figure 10. TEM image of a core-shell $v$-phase $+\mathrm{Mg}_{2} \mathrm{Si}+\mathrm{Al}-\mathrm{Zn}-\mathrm{Cu}-\mathrm{Mg}$ particle in the AA4047/AA7075 transition zone. 
Table 5. EDS of the core-shell $v$-phase $/ \mathrm{Mg}_{2} \mathrm{Si} / \mathrm{Al}-\mathrm{Zn}-\mathrm{Cu}-\mathrm{Mg}$ particle.

\begin{tabular}{cccccc}
\hline Probe Point & Mg & Al & Si & Cu & Zn \\
\hline $1-4$ & $36.7 \pm 6.7$ & $29.9 \pm 6.3$ & - & $15.7 \pm 2.7$ & $17.1 \pm 4.5$ \\
$5-6$ & $60.6 \pm 1.2$ & $2.8 \pm 0.3$ & $35.4 \pm 0.8$ & $1.2 \pm 0.2$ & - \\
7 & $5.5 \pm 1.4$ & $87.6 \pm 5.9$ & - & $5.7 \pm 0.5$ & $1.2 \pm 0.4$ \\
8 & $9.2 \pm 1.4$ & $75.5 \pm 3.6$ & - & $1.54 \pm 0.4$ & $13.7 \pm 3.4$ \\
\hline
\end{tabular}

\subsubsection{AA4047 As-Deposited Zone I}

It was shown above (Figure 2a) that the microstructure of the as-deposited AA4047 zone I is composed of $\alpha-\mathrm{Al}$ dendrites and interdendritic Al/Si eutectics. TEM images of the thin foils cut off from this zone also allow the observation of small $<6 \mu \mathrm{m} \alpha$-Al grains with a necklace of $\mathrm{Al} / \mathrm{Si}$ eutectics (Figure 11a). Fine 300-700 nm Si particles were detected both in the interdendritic spaces (Figure 11b,d) and inside the $\alpha$-Al grains (Figure 11c).

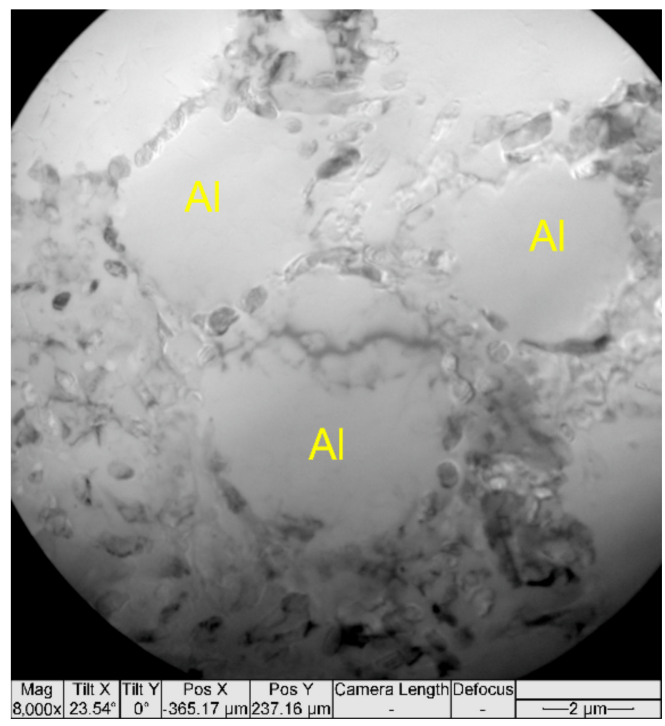

(a)



(c)

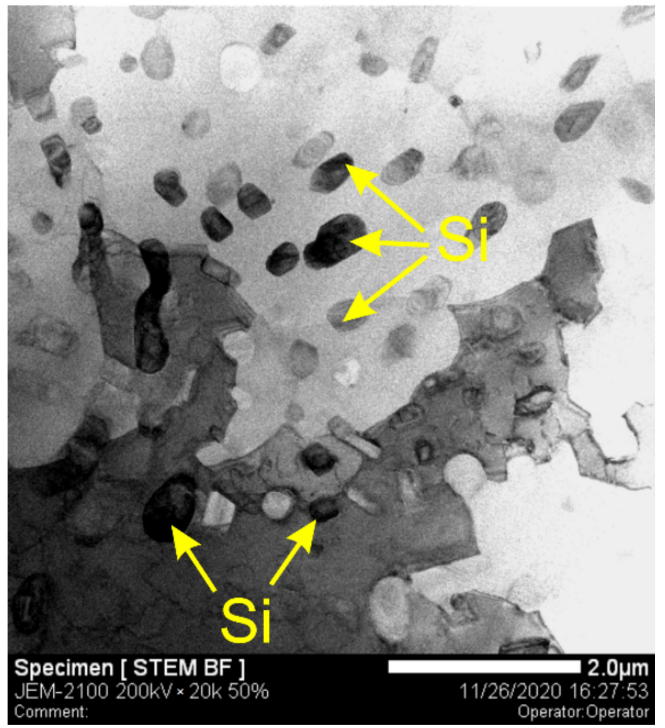

(b)

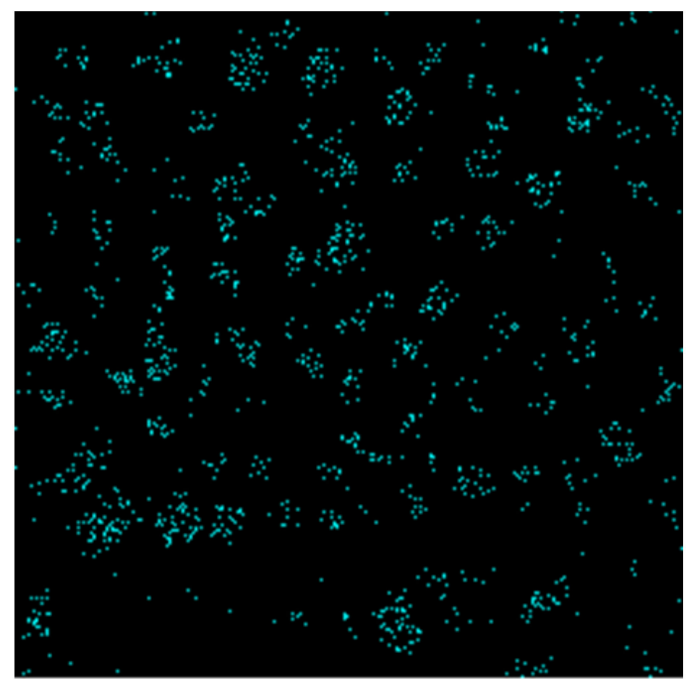

Si Ka1

(d)

Figure 11. Small $\alpha$-Al grains with a necklace of $\mathrm{Al} / \mathrm{Si}$ eutectics (a), (b) $\mathrm{Al} / \mathrm{Si}$ eutectic region, (c) $\mathrm{Si}$ crystallites inside the $\alpha-\mathrm{Al}$ grains and (d) EDS map of Si distribution corresponding to (b). 
Iron-rich Al-Fe-Si particles (Figure 12a), with their chemical composition presented in Figure $12 b-d$, were detected in this zone. According to the XRD results, in Figure 6, these particles might have been identified as $\mathrm{Fe}_{2} \mathrm{Al}_{3} \mathrm{Si}_{3}$ and $\mathrm{Fe}_{2} \mathrm{Al}_{2} \mathrm{Si}_{3}$, while their EDS compositions showed them close to that of $\mathrm{Fe}_{2} \mathrm{Al}_{8} \mathrm{Si}[39,40]$ plausibly because of the limited EDS probe accuracy and contamination with aluminum.
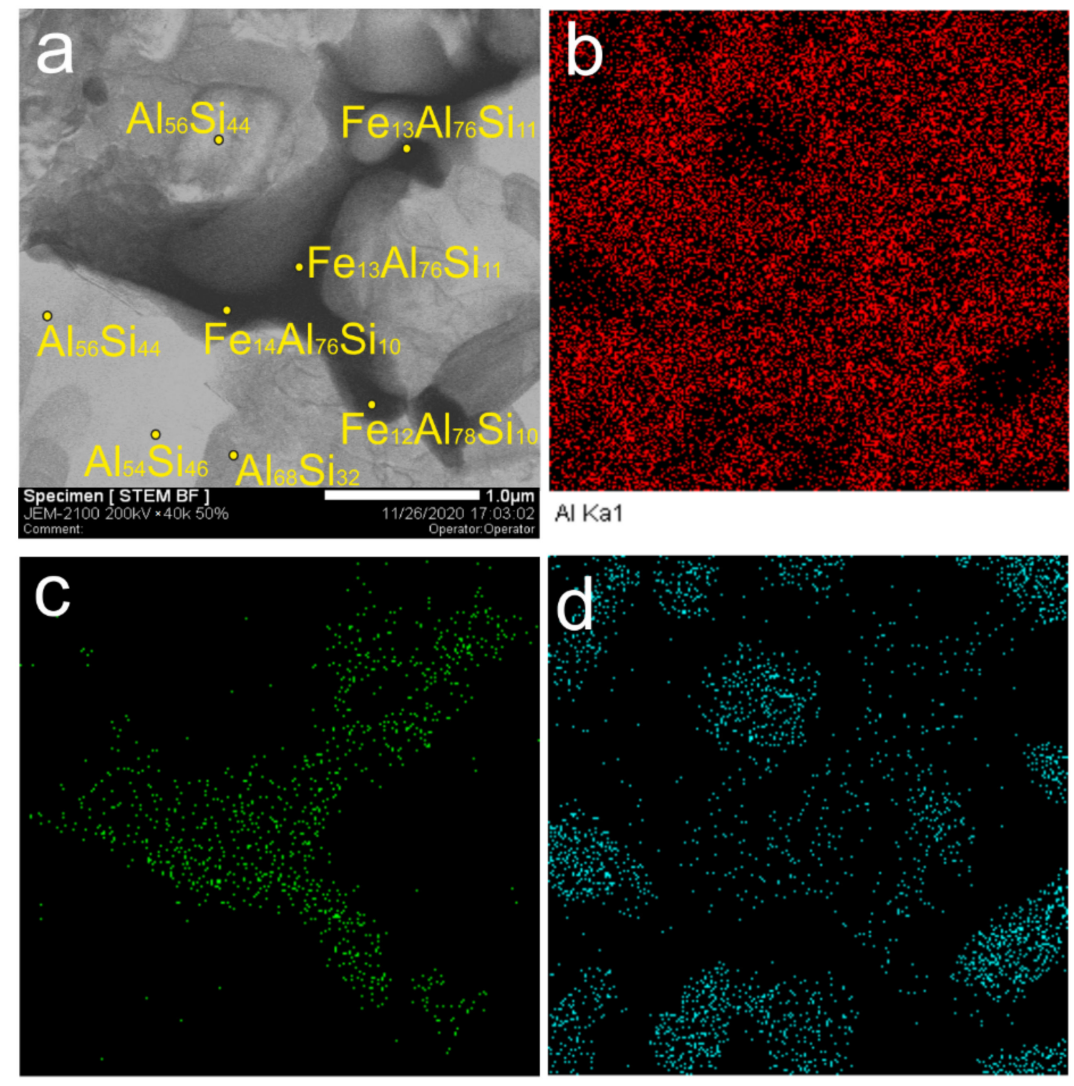

Fe Ka1

Si Ka1

Figure 12. Iron-rich particles $(\mathbf{a}-\mathbf{c})$ and silicon-rich $(\mathbf{a}, \mathbf{d})$ particles.

\subsection{Mechanical Characteristics}

Dog bone-shaped samples for tensile testing were cut off from the additive-deposited wall so that the transfer zone II would be in the middle of the gauge length. Stress-strain curves obtained from the test were of the type inherent in the ductile materials (Figure 13a) and allowed for the determination of the strength characteristics as follows: mean yield stress limit $122.7 \pm 15.2 \mathrm{MPa}$, mean ultimate stress limit $180.5 \pm 2.5 \mathrm{MPa}$ and mean elongation to failure $7.9 \pm 1.3 \%$.

The microhardness profile was obtained along the wall height to reveal the high hardness of the AA7075 heat-affected zone and the bottom part of the rather narrow transition zone followed by a sharp fall in its top half to the numbers typical of the deposited AA4047 (Figure 13b). The microhardness number distribution coincides with that of the AA7075 alloying components, such as $\mathrm{Mg}, \mathrm{Zn}$ and $\mathrm{Cu}$ (Figure 5).

It was observed that a fracture occurred within the as-deposited AA4047 zone I (Figure 14a,b) characterized by the presence of $\alpha$-Al dendrites and interdendritic $\mathrm{Al} / \mathrm{Si}$ eutectics (see enlarged insets to Figure 14b). Such a result was not a surprise if taking into account the differences in the strength and structure of the AA7075, transition zone and as-deposited AA4047. 


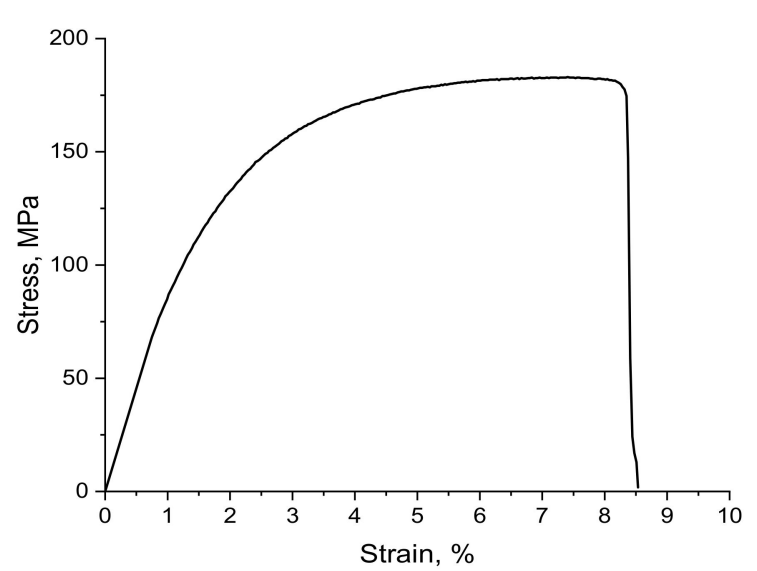

(a)

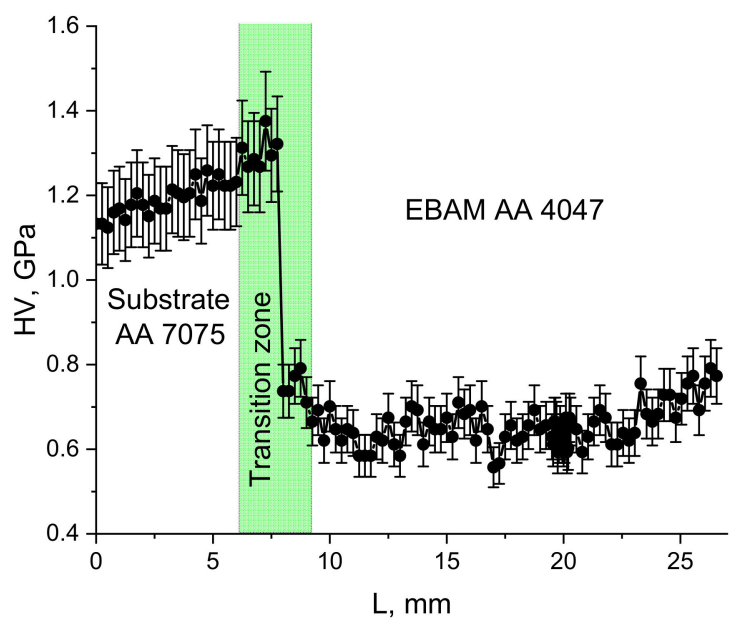

(b)

Figure 13. Stress-strain curve for tensile test (a) and microhardness profile (b).
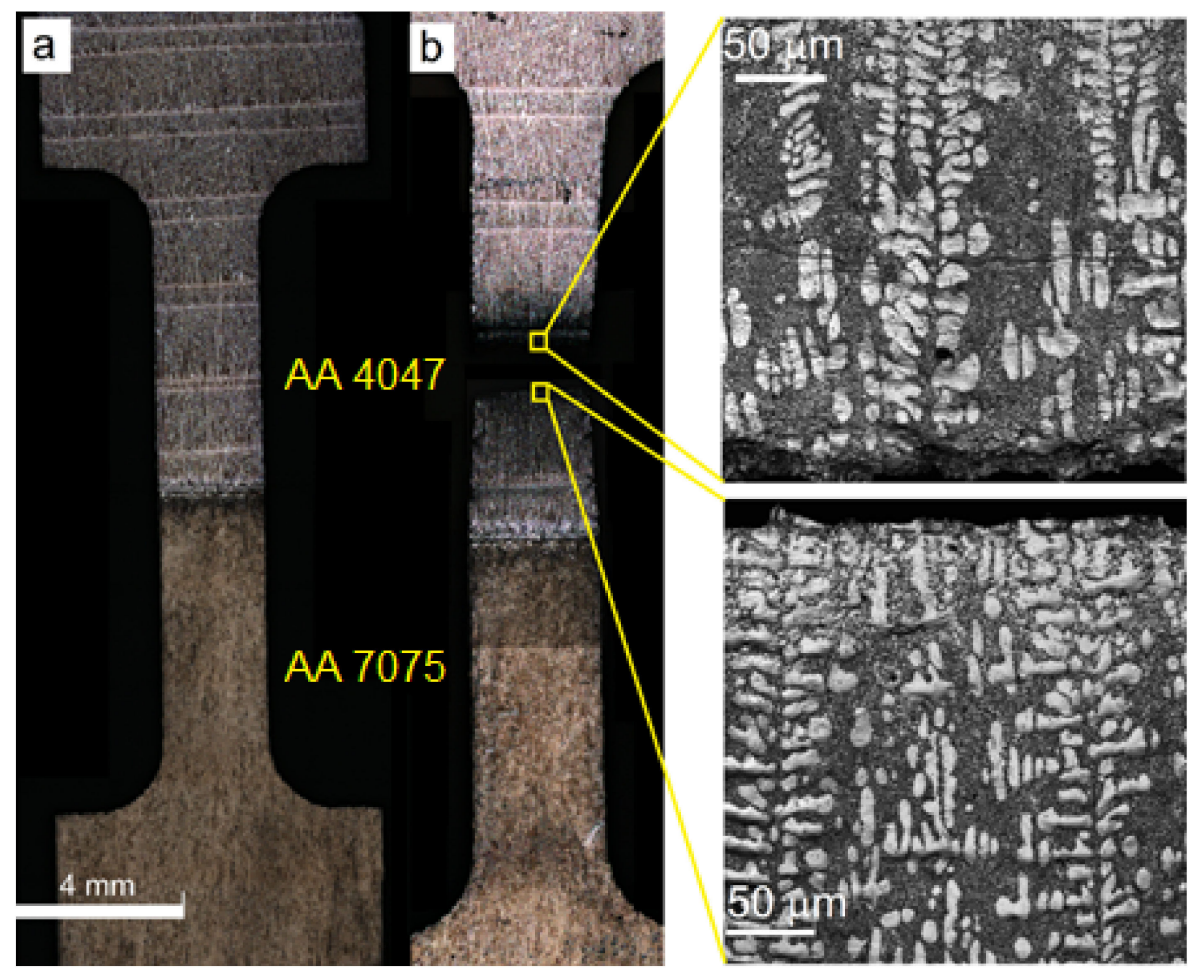

Figure 14. Tensile sample before (a) and after (b) fracture with dendritic structures in the vicinity of fracture.

The fracture occurred in the as-deposited AA4047 zone where there were no components other than Al-dendrites, excess Si-crystallites and Al/Si eutectics. It could be that Si-crystallites (shown inside the yellow circles in Figure 15a,b) served as stress concentrators, but this as-cast structure was heterogeneous enough by itself. The fracture surface is characterized by the presence of dimples, ridges and $\sim 3 \mu \mathrm{m}$ cells (Figure 15a,b). Despite the fact that no deformation neck formed, the fracture may be related to the viscous type. 


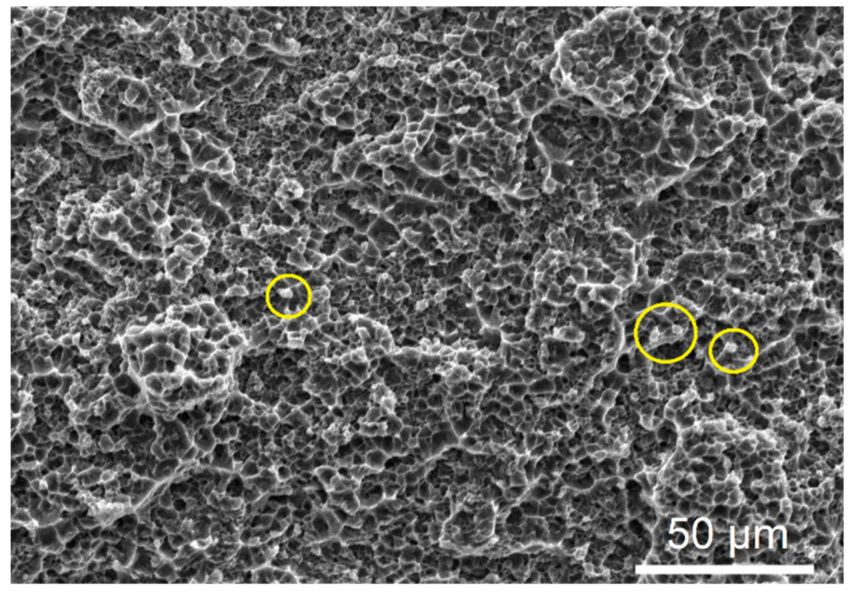

(a)

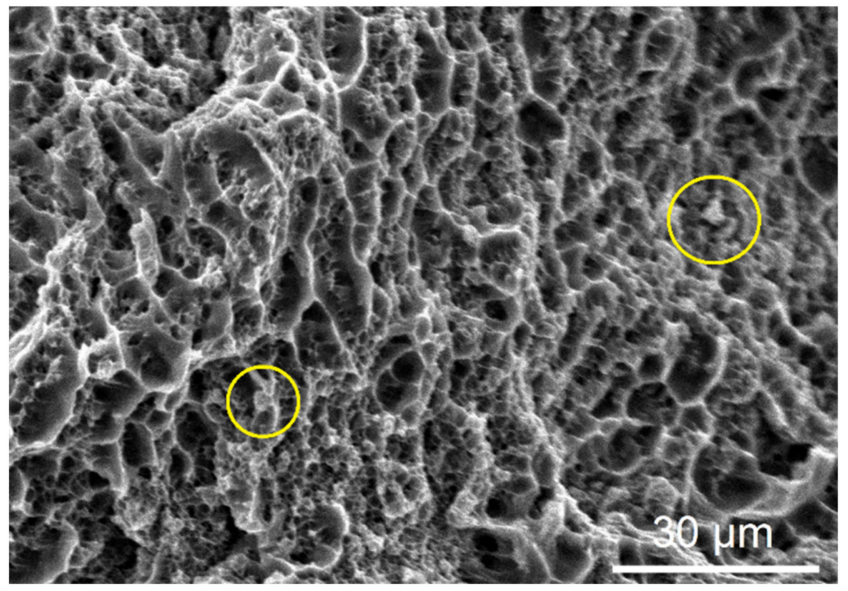

(b)

Figure 15. Fracture surface at magnification (a) $\times 500$ and (b) $\times 1000$.

\subsection{Corrosion}

Potentiodynamic corrosion testing was carried on samples cut off from all three zones, namely, as-deposited AA4047 zone I, transition zone II and heat-affected AA7075 substrate zone III. The minimum value of the corrosion potential Ecorr was observed for a sample from transition zone II (Figure 16, Table 6), which is only 29 and $215 \mathrm{mV}$ less than that of AA7075 substrate zone III and as-deposited AA4047 zone I, respectively.

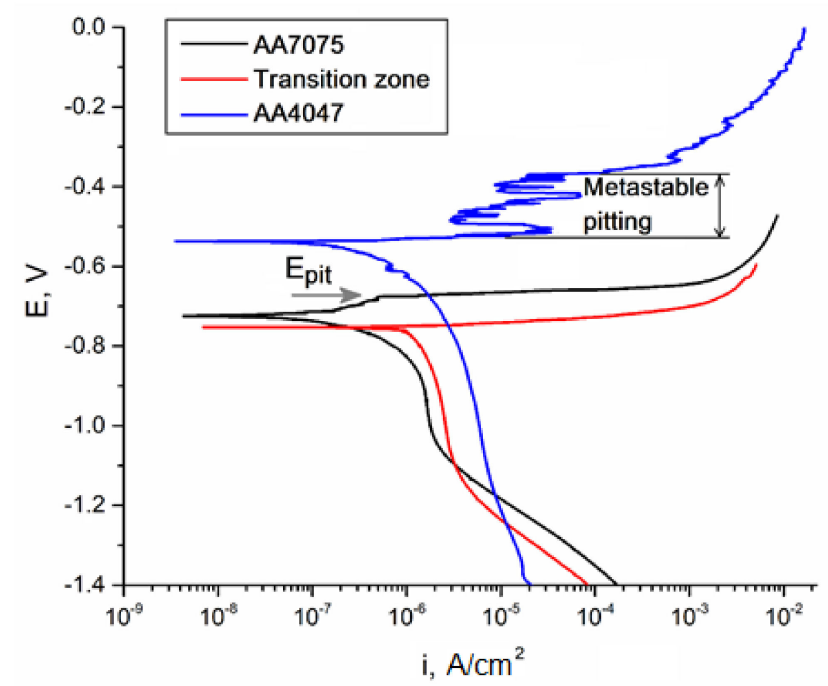

Figure 16. Potentiodynamic polarization curve for studied samples.

Table 6. Polarization parameters for studied samples.

\begin{tabular}{ccc}
\hline Zone of interest & $\mathbf{E}_{\mathbf{c o r r}}, \mathbf{~} \mathbf{~ V}$ & $\mathbf{i}_{\text {corr }}, \mathbf{A} / \mathbf{c m}^{\mathbf{2}}$ \\
\hline AA4047 & -539 & $7.7 \times 10^{-8}$ \\
Transition zone & -754 & $1.22 \times 10^{-6}$ \\
AA7075-T42 & -725 & $3.25 \times 10^{-7}$ \\
\hline
\end{tabular}

Let us note that the mean corrosion potential behavior is reversed as compared to that of the corrosion current density; i.e., the maximum current density corresponds to the minimum corrosion potential and vice versa (Table 6). Hence, the transition zone demonstrated minimum corrosion potential and maximum corrosion current density, while as-deposited AA4047 is characterized by the maximum corrosion potential and minimum current density. 
An anodic branch of the as-deposited AA4047 polarization curve is characterized by the presence of oscillations, which can be a symptom of metastable pitting; this starts at $-518 \mathrm{mV}$ and ends at $-366 \mathrm{mV}$. It was not possible to measure the pitting potential on the transition zone metal because of the intense dissolution of the numerous intermetallic particles that started just after reaching the corresponding $\mathrm{E}_{\mathrm{corr}}$ value; i.e., no passivation behavior was observed. A pitting potential value for the heat-affected AA7075 substrate was $-678 \mathrm{mV}$.

The samples subjected to corrosion tests were then washed, dried and examined using a confocal optical microscope for surface corrosion damages. The surface of as-deposited AA4047 zone I can be described by the presence of isolated shallow and $\sim 10-\mu \mathrm{m}$-sized pits (Figure 17a,c) without any noticeable corrosion-affected areas (Figure 17a).
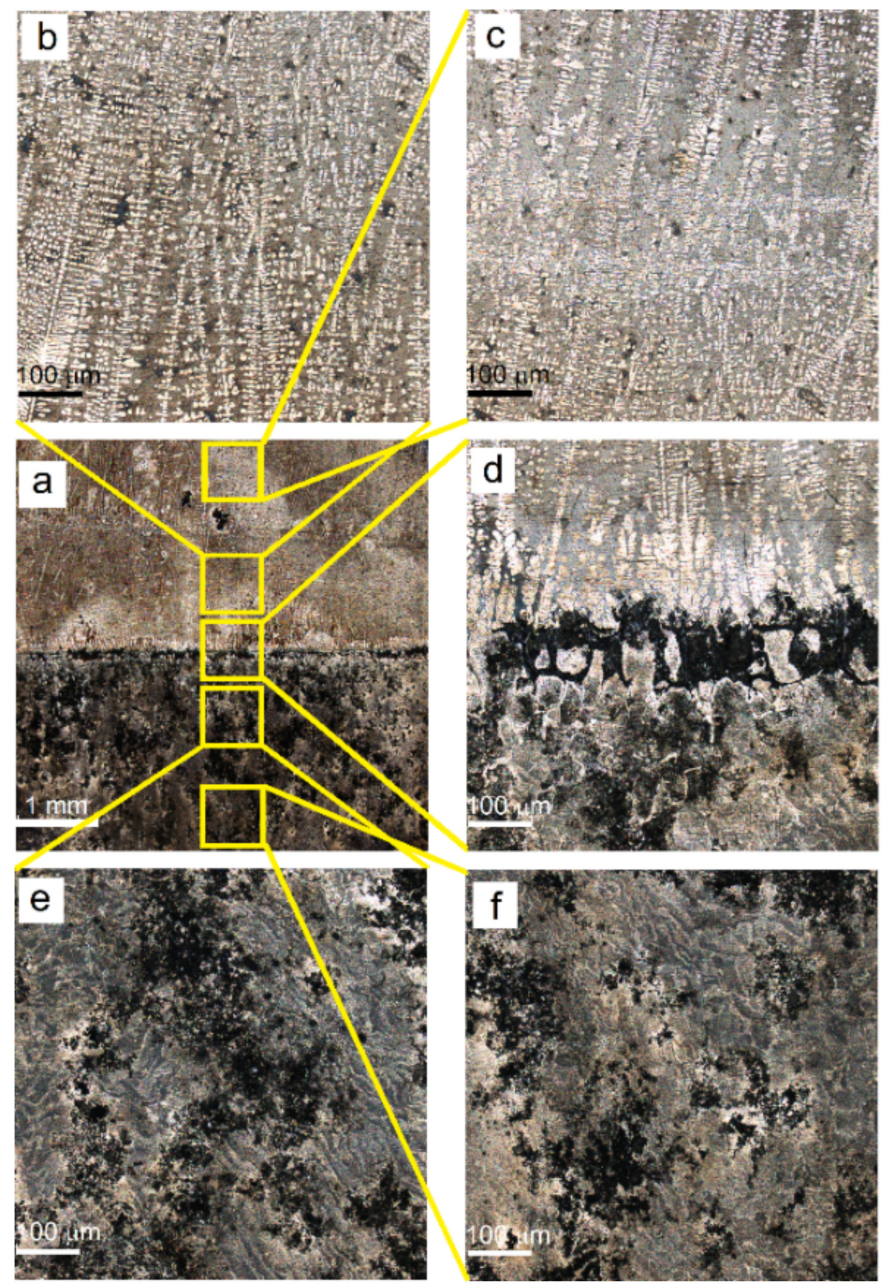

Figure 17. Optical confocal images of corroded surfaces of the samples. Corroded surface macrograph (a), as-deposited AA4047 zones (b,c), transition zone (d), heat-affected AA7075 (e), as-received AA7075-T42 (f).

No changes were observed in zone I or as it approached closer to transition zone II (Figures 17a,b and 18b). 


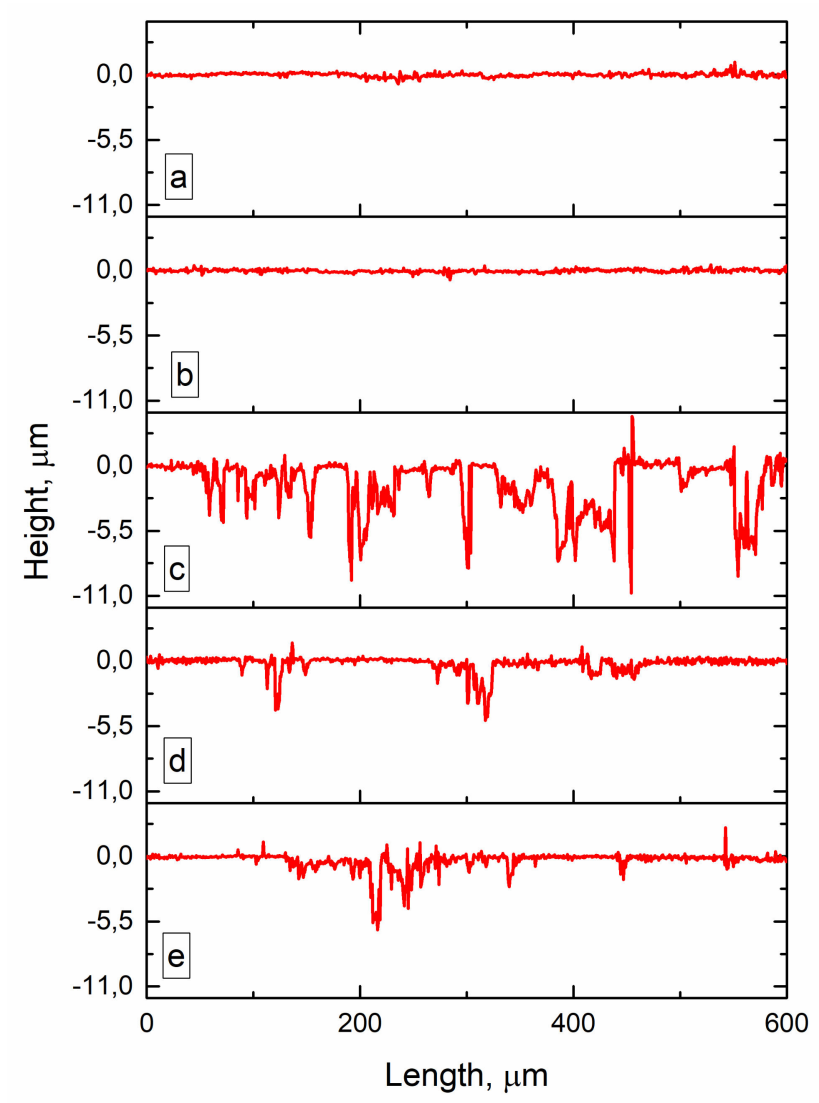

Figure 18. The surface profiles after corrosion according to zones shown in Figure 15. As-deposited AA4047 zones (a,b), transition zone (c), heat-affected AA7075 (d), as-received AA7075-T42 (e).

Notable corrosion occurred on the surface of the transition zone (Figure 17a,d). Presumably, corrosion in this zone developed both by grain boundaries and particle agglomerates similar to those observed in Figure $3 \mathrm{~d}$. Deep pits of up to $11 \mu \mathrm{m}$ in depth formed there as a result of corrosion (Figure 18c). Less deep $(<5 \mu \mathrm{m})$ and smaller area pits were also observed in the heat-affected AA7075, just below the transition zone (Figures 17a,e and 18d). Almost the same type of corrosion surface pattern with $\sim 6-\mu \mathrm{m}$-deep corrosion pits was observed in the heat-affected zone of the AA7075 substrate (Figure 17f). These abovedescribed results allow the suggestion that a strong correlation exists between the structural state and the corrosion behavior on the samples investigated.

\section{Discussion}

The melting and transferring of AA4047 wire to the melt pool formed on an AA7075 substrate by an electron beam allowed us to obtain a narrow transition zone between two alloys where components of both alloys admixed and solidified in the form of aluminum alloy dendrites, interdendritic spaces filled with $\mathrm{Al} / \mathrm{Si}$ eutectics and coarse intermetallic particles (agglomerates). According to the EDS profiles in Figure 5, high-density elements, such as $\mathrm{Zn}$ and $\mathrm{Cu}$, stay in the bottom part of the transition zone as well as lighter-than-Al magnesium despite the fact that its somewhat increased concentration was detected in the top part of the wall. Such a finding may be caused by some floating of the magnesium in partial layer-by-layer remelting. The distribution of silicon across the transition zone also shows a sharp threshold between the bottom and top parts of the zone.

Therefore, a sharp concentration threshold exists instead of a somewhat wide transition zone. Such a finding can only be explained by the lack of intense intermixing in the melted pool. Several factors determine the intensity of metal intermixing in the pool, such as the intensity of heating, convection and density differences. The intensity of convection 
is dependent on the heat input, which has to be limited to also avoid the boiling and loss of such alloying elements as $\mathrm{Mg}$ and $\mathrm{Zn}$.

The phase composition of the transition zone is determined by the distribution of alloying elements and impurities. The magnesium-, copper- and zinc-rich bottom part contains all particles inherent in the AA7075 substrate, while the top part shows more $\mathrm{Si}$ in the form of the core-shell $\mathrm{Mg}_{2} \mathrm{Si} / v$-phase particles. The as-deposited AA-4047 is composed of aluminum dendrites and $\mathrm{Al} / \mathrm{Si}$ eutectics, thus representing as-cast AA4047 structures without any reinforcing fine and coherent precipitates. The microhardness test showed its hardness at the level of $0.6 \mathrm{GPa}$ as compared to 1.25 and $1.3 \mathrm{GPa}$ of the AA-7075 heat-affected zone and bottom part of the transition zone, respectively. Therefore, the tensile test results showed that fracture occurred in this zone with the minimum strength as compared to those of AA7075 substrate and transition zone.

It was shown that the transition zone was enriched by $\mathrm{Si}$ and, therefore, more $\mathrm{Mg}_{2} \mathrm{Si}$ precipitated there, thus causing the most intense corrosion. It is also known [41] that both $\mathrm{Mg}$ - and Si-containing particles, such as S-phase $\left(\mathrm{Al}_{2} \mathrm{CuMg}\right)$ and $\mathrm{Mg}_{2} \mathrm{Si}$, serve as anodic ones with respect to their embedding in the $\alpha$-Al matrix. Therefore, these particles are dissolved in $\mathrm{NaCl}$ and leave the deep pits (Figure 18c). The AA7075 substrate contains less $\mathrm{Si}$, and, therefore, there are less $\mathrm{Mg}_{2} \mathrm{Si}$ particles to be subjected to corrosion.

On the contrary, cathodic Si and Fe-Si particles reveal high resistance to corrosion but provoke preferential and uniform dissolution of the matrix [42] instead of the formation of deep pits in the as-deposited AA4047 zone.

\section{Conclusions}

The additive electron beam wire-feed deposition of AA4047 on a high-strength AA7075 substrate resulted in the formation of a narrow defectless and resilient transition zone characterized by a sharp threshold in the distribution of alloying elements and, correspondingly, the inhomogeneous distribution of intermetallic phases. Such a transition zone is a result of using in situ adjustment of the heat input, which allowed us to minimize the intermixing of the elements in the melted pool and obtain relatively "cold" deposition conditions.

The minimum and maximum values of a corrosion potential were obtained on the surfaces of the as-deposited AA4047 and AA7075/ AA4047 transition zone, respectively. The precipitation of anodic $\mathrm{Mg}_{2} \mathrm{Si}$ and $\mathrm{Al}_{2} \mathrm{CuMg}$ in the transition zone caused their intense dissolution and pitting.

Author Contributions: Conceptualization, A.F. and S.T.; methodology, A.F. and S.T.; software, V.U. and N.S. (Nikolay Shamarin); validation, A.F., V.U. and N.S. (Nikolay Shamarin); formal analysis, A.F., V.U., N.S. (Nikolay Shamarin), A.V., A.C., N.S. (Nikolay Savchenko) and D.G.; investigation, A.F., V.U., N.S. (Nikolay Shamarin), A.V., A.C., N.S. (Nikolay Savchenko) and D.G.; resources, A.F. and S.T.; writing—original draft preparation, A.F., V.U. and S.T.; writing—review and editing, A.F., V.U. and S.T.; visualization, A.F. and S.T.; supervision, A.F., V.R., E.K. and S.T.; project administration, A.F., V.R. and S.T.; funding acquisition, E.K. All authors have read and agreed to the published version of the manuscript.

Funding: The work was performed according to the Government research assignment for ISPMS SB RAS, project FWRW-2019-0034.

Institutional Review Board Statement: Not applicable.

Informed Consent Statement: Not applicable.

Data Availability Statement: The data presented in this study are available on request from the corresponding author.

Conflicts of Interest: The authors declare no conflict of interest. 


\section{References}

1. Owoputi, A.; Inambao, F. A Review of Functionally Graded Materials: Fabrication Processes and Applications. Int. J. Appl. Eng. Res. 2021, 13, 16141-16151.

2. Kiss, Z.; Varga, B. Functionally Graded Aluminium Alloys. Bull. Transilv. Univ. Braşov Ser. I Eng. Sci. 2014, 7, 33.

3. Sobczak, J.J.; Drenchev, L. Metallic Functionally Graded Materials: A Specific Class of Advanced Composites. J. Mater. Sci. Technol. 2013, 29, 297-316. [CrossRef]

4. Fracchia, E.; Lombardo, S.; Rosso, M. Case study of a functionally graded aluminum part. Appl. Sci. 2018, 8, 1113. [CrossRef]

5. Ahmed, A.; El-Hadad, S.; Reda, R.; Dawood, O. Microstructure control in functionally graded Al-Si castings. Int. J. Cast Met. Res. 2019, 32, 67-77. [CrossRef]

6. Ulukoy, A.; Topcu, M.; Tasgetiren, S. Experimental investigation of aluminum matrix functionally graded material: Microstructural and hardness analyses, fretting, fatigue, and mechanical properties. Proc. Inst. Mech. Eng. Part J J. Eng. Tribol. 2016, 230, 143-155. [CrossRef]

7. Rajan, T.P.D.; Jayakumar, E.; Pai, B.C. Developments in solidification processing of functionally graded aluminium alloys and composites by centrifugal casting technique. Trans. Indian Inst. Met. 2012, 65, 531-537. [CrossRef]

8. Hu, S.; Gagnoud, A.; Fautrelle, Y.; Moreau, R.; Li, X. Fabrication of aluminum alloy functionally graded material using directional solidification under an axial static magnetic field. Sci. Rep. 2018, 8, 1-13. [CrossRef]

9. Kim, D.; Park, K.; Chang, M.; Joo, S.; Hong, S.; Cho, S.; Kwon, H. Fabrication of functionally graded materials using aluminum alloys via hot extrusion. Metals 2019, 9, 210. [CrossRef]

10. Loh, G.H.; Pei, E.; Harrison, D.; Monzón, M.D. An overview of functionally graded additive manufacturing. Addit. Manuf. 2018, 23, 34-44. [CrossRef]

11. Hofmann, D.C.; Kolodziejska, J.; Roberts, S.; Otis, R.; Dillon, R.P.; Suh, J.O.; Liu, Z.K.; Borgonia, J.P. Compositionally graded metals: A new frontier of additive manufacturing. J. Mater. Res. 2014, 29, 1899-1910. [CrossRef]

12. Cong, B.; Qi, Z.; Qi, B.; Sun, H.; Zhao, G.; Ding, J. A comparative study of additively manufactured thin wall and block structure with Al-6.3\%Cu alloy using cold metal transfer process. Appl. Sci. 2017, 7, 275. [CrossRef]

13. Ryan, E.M.; Sabin, T.J.; Watts, J.F.; Whiting, M.J. The influence of build parameters and wire batch on porosity of wire and arc additive manufactured aluminium alloy 2319. J. Mater. Process. Technol. 2018, 262, 577-584. [CrossRef]

14. Ortega, A.G.; Corona Galvan, L.; Salem, M.; Moussaoui, K.; Segonds, S.; Rouquette, S.; Deschaux-Beaume, F. Characterisation of 4043 aluminium alloy deposits obtained by wire and arc additive manufacturing using a Cold Metal Transfer process. Sci. Technol. Weld. Join. 2019, 24, 538-547. [CrossRef]

15. Köhler, M.; Fiebig, S.; Hensel, J.; Dilger, K. Wire and arc additive manufacturing of aluminum components. Metals 2019, 9, 608. [CrossRef]

16. Uzan, N.E.; Ratzker, B.; Landau, P.; Kalabukhov, S.; Frage, N. Compressive creep of AlSi10Mg parts produced by selective laser melting additive manufacturing technology. Addit. Manuf. 2019, 29, 100788. [CrossRef]

17. Girelli, L.; Giovagnoli, M.; Tocci, M.; Pola, A.; Fortini, A.; Merlin, M.; La Vecchia, G. Evaluation of the impact behaviour of AlSi10Mg alloy produced using laser additive manufacturing. Mater. Sci. Eng. A 2019, 748, 38-51. [CrossRef]

18. Rosenthal, I.; Stern, A.; Frage, N. Microstructure and Mechanical Properties of AlSi10Mg Parts Produced by the Laser Beam Additive Manufacturing (AM) Technology. Metallogr. Microstruct. Anal. 2014, 3, 448-453. [CrossRef]

19. Giovagnoli, M.; Tocci, M.; Fortini, A.; Merlin, M.; Ferroni, M.; Migliori, A.; Pola, A. Effect of different heat-treatment routes on the impact properties of an additively manufactured AlSi10Mg alloy. Mater. Sci. Eng. A 2021, 802, 140671. [CrossRef]

20. Zhang, Y.; Bandyopadhyay, A. Direct fabrication of bimetallic Ti6Al4V+Al12Si structures via additive manufacturing. Addit. Manuf. 2019, 29, 100783. [CrossRef]

21. Hadadzadeh, A.; Shalchi Amirkhiz, B.; Shakerin, S.; Kelly, J.; Li, J.; Mohammadi, M. Microstructural investigation and mechanical behavior of a two-material component fabricated through selective laser melting of AlSi10Mg on an Al-Cu-Ni-Fe-Mg cast alloy substrate. Addit. Manuf. 2019, 31, 100937. [CrossRef]

22. Dolev, O.; Osovski, S.; Shirizly, A. Ti-6Al-4V hybrid structure mechanical properties-Wrought and additive manufactured powder-bed material. Addit. Manuf. 2021, 37, 101657. [CrossRef]

23. Reith, M.; Franke, M.; Schloffer, M.; Körner, C. Processing 4th generation titanium aluminides via electron beam based additive manufacturing-characterization of microstructure and mechanical properties. Materialia 2020, 14, 100902. [CrossRef]

24. Breuning, C.; Arnold, C.; Markl, M.; Körner, C. A multivariate meltpool stability criterion for fabrication of complex geometries in electron beam powder bed fusion. Addit. Manuf. 2021, 45. [CrossRef]

25. Kotzem, D.; Arold, T.; Niendorf, T.; Walther, F. Influence of specimen position on the build platform on the mechanical properties of as-built direct aged electron beam melted Inconel 718 alloy. Mater. Sci. Eng. A 2020, 772, 138785. [CrossRef]

26. Kotzem, D.; Arold, T.; Niendorf, T.; Walther, F. Damage tolerance evaluation of E-PBF-manufactured inconel 718 strut geometries by advanced characterization techniques. Materials 2020, 13, 247. [CrossRef]

27. Kotzem, D.; Dumke, P.; Sepehri, P.; Tenkamp, J.; Walther, F. Effect of miniaturization and surface roughness on the mechanical properties of the electron beam melted superalloy Inconel ${ }^{\circledR}$ 718. Prog. Addit. Manuf. 2020, 5, 267-276. [CrossRef]

28. Kotzem, D.; Tazerout, D.; Arold, T.; Niendorf, T.; Walther, F. Failure mode map for E-PBF manufactured Ti6Al4V sandwich panels. Eng. Fail. Anal. 2021, 121, 105159. [CrossRef] 
29. Bian, H.; Aoyagi, K.; Zhao, Y.; Maeda, C.; Mouri, T.; Chiba, A. Microstructure refinement for superior ductility of Al-Si alloy by electron beam melting. Addit. Manuf. 2020, 32, 100982. [CrossRef]

30. Sun, S.; Zheng, L.; Peng, H.; Zhang, H. Microstructure and mechanical properties of Al-Fe-V-Si aluminum alloy produced by electron beam melting. Mater. Sci. Eng. A 2016, 659, 207-214. [CrossRef]

31. Brice, C.A.; Tayon, W.A.; Newman, J.A.; Kral, M.V.; Bishop, C.; Sokolova, A. Effect of compositional changes on microstructure in additively manufactured aluminum alloy 2139. Mater. Charact. 2018, 143, 50-58. [CrossRef]

32. Utyaganova, V.R.; Filippov, A.V.; Shamarin, N.N.; Vorontsov, A.V.; Savchenko, N.L.; Fortuna, S.V.; Gurianov, D.A.; Chumaevskii, A.V.; Rubtsov, V.E.; Tarasov, S.Y. Controlling the porosity using exponential decay heat input regimes during electron beam wire-feed additive manufacturing of Al-Mg alloy. Int. J. Adv. Manuf. Technol. 2020, 108, 2823-2838. [CrossRef]

33. Kenevisi, M.S.; Lin, F. Selective electron beam melting of high strength Al2024 alloy; microstructural characterization and mechanical properties. J. Alloys Compd. 2020, 843, 155866. [CrossRef]

34. Osipovich, K.S.; Astafurova, E.G.; Chumaevskii, A.V.; Kalashnikov, K.N.; Astafurov, S.V.; Maier, G.G.; Melnikov, E.V.; Moskvina, V.A.; Panchenko, M.Y.; Tarasov, S.Y.; et al. Gradient transition zone structure in "steel-copper" sample produced by double wire-feed electron beam additive manufacturing. J. Mater. Sci. 2020, 55, 9258-9272. [CrossRef]

35. Osipovich, K.; Vorontsov, A.; Chumaevskii, A.; Gurianov, D.; Shamarin, N.; Savchenko, N.; Kolubaev, E. Characterization of a Bimetallic Multilayered Composite "Stainless Steel/Copper" Fabricated with Wire-Feed Electron Beam Additive Manufacturing. Metals 2021, 11, 1151. [CrossRef]

36. Filippov, A.V.; Khoroshko, E.S.; Shamarin, N.N.; Savchenko, N.L.; Moskvichev, E.N.; Utyaganova, V.R.; Kolubaev, E.A.; Smolin, A.Y.; Tarasov, S.Y. Characterization of gradient CuAl-B4C composites additively manufactured using a combination of wire-feed and powder-bed electron beam deposition methods. J. Alloys Compd. 2021, 859, 157824. [CrossRef]

37. Utyaganova, V.; Filippov, A.; Tarasov, S.; Shamarin, N.; Gurianov, D.; Vorontsov, A.; Chumaevskii, A.; Fortuna, S.; Savchenko, N.; Rubtsov, V.; et al. Characterization of AA7075/AA5356 gradient transition zone in an electron beam wire-feed additive manufactured sample. Mater. Charact. 2021, 172, 110867. [CrossRef]

38. Gharbi, O.; Kairy, S.; Lima, P.; Jiang, D.; Nicklaus, J.; Birbilis, N. Microstructure and corrosion evolution of additively manufactured aluminium alloy AA7075 as a function of ageing. npj Mater. Degrad. 2019, 3, 1-11. [CrossRef]

39. Mondolfo, L.F. Al-Si Aluminum-Silicon System. In Aluminum Alloys; Mondolfo, L.F., Ed.; Butterworth-Heinemann: Oxford, UK, 1976; pp. 368-376. ISBN 978-0-408-70932-3.

40. Mbuya, T.O.; Odera, B.; $\mathrm{Ng}^{\prime}$ Ang'A, S. Influence of iron on castability and properties of aluminium silicon alloys: Literature review. Int. J. Cast Met. Res. 2003, 16, 451-465. [CrossRef]

41. Birbilis, N.; Buchheit, R. Electrochemical characteristics of intermetallic phases in aluminum alloys: An experimental survey and discussion. J. Electrochem. Soc. 2005, 152, B140-B151. [CrossRef]

42. Cabrini, M.; Lorenzi, S.; Pastore, T.; Pellegrini, S.; Ambrosio, E.; Calignano, F.; Manfredi, D.; Pavese, M.; Fino, P. Effect of heat treatment on corrosion resistance of DMLS AlSi10Mg alloy. Electrochim. Acta 2016, 206, 346-355. [CrossRef] 